Article

\title{
Adoption of Energy Efficiency Measures in Renovation of Single-Family Houses: A Comparative Approach ${ }^{\dagger}$
}

\author{
Shoaib Azizi *(D), Gireesh Nair and Thomas Olofsson (D) \\ Department of Applied Physics and Electronics, Umeå University, 90187 Umeå, Sweden; \\ gireesh.nair@umu.se (G.N.); thomas.olofsson@umu.se (T.O.) \\ * Correspondence: shoaib.azizi@umu.se; Tel.: +46-90-786-6845 \\ + This paper is an extended and improved version of a study presented in ACEEE 2018 Conference, \\ Pacific Groove, CA, USA, 12-17 August 2018.
}

Received: 23 September 2020; Accepted: 17 November 2020; Published: 19 November 2020

check for updates

\begin{abstract}
Inclusion of energy efficiency measures (EEMs) in the renovation of the single-family housing stock can unlock the potential for much-needed energy efficiency to tackle climate change. Energy renovation (ER) in single-family houses is often promoted as an aggregate process, and EEMs are treated homogenously without sufficient attention to their differences. This study applies a comparative analysis on common EEMs using chi-square test to investigate the influence of factors already found affecting the implementation of ER. This paper addresses the "personal" and "house-related" factors influencing the adoption of EEMs regardless of motives or barriers leading the adopters' decisions. This strategy is useful to highlight the contexts leading to an increase in the adoption rate of different EEMs. The analysis is based on a questionnaire survey mailed in spring 2017 to 1550 single-family homeowners in the northern region of Sweden. Approximately $60 \%$ of respondents showed interest in adopting at least one EEM if they implement a major renovation. About $46 \%$ of respondents stated to have at least one indoor environmental problem (IEP) in their houses, and IEPs are found to have significant relations with homeowners' interest to adopt several different EEMs. The policy implications related to different EEMs are discussed.
\end{abstract}

Keywords: energy renovation; influential factors; implementation; homeowners' perception; indoor environmental quality

\section{Introduction}

Buildings are a major sector responsible for global warming as they account for 30\% of the world's final energy use [1], and a quarter of greenhouse gas emissions (GHGE) [2]. These shares are even larger for the European building stock, which are responsible for $40 \%$ of final energy use and $36 \%$ of GHGE [3]. Despite the efforts to improve energy efficiency in residential buildings, the energy used in this sector has increased in the last few decades and is expected to grow worldwide in the future [4]. Political aspirations to mitigate climate change have led to devise several policy instruments to improve energy efficiency in the European Union. The Energy Efficiency Directive (EED) and the Energy Performance of Buildings Directive (EPBD) are the two well-known legislative documents on buildings' energy efficiency in Europe [5,6]. In addition to the policies at the European level, Sweden has undertaken several initiatives to drive and facilitate energy-efficient renovation in the building sector [7].

Single-family houses comprise a large share of dwellings in Sweden, which are responsible for $53 \%$ of GHGE from the residential sector, equivalent to $2.62 \mathrm{MtCO}_{2}$ per year [8]. Single-family houses 
are often occupied by their owners. Unlike the multi-family buildings, which are often managed by municipality companies, private companies, and housing associations [9], the owners of single-family houses have more freedom on their investment decisions to improve their dwellings' energy efficiency. Buildings are usually considered to last over 50 years, hence, the majority of existing buildings will be in use in the coming decades [10]. The annual rate of construction of new dwellings in Sweden is just about $1 \%$ [11]. This implies the importance of existing housing stock to attain environmental and political targets for a low-carbon future. Renovation provides an opportunity to improve the energy efficiency of existing buildings. Home renovation could include (i) non-energy improvement measures such as kitchen and bathroom renovation and/or (ii) energy efficiency measures (EEMs) such as replacing the inefficient components in a building with more energy-efficient ones and improving the insulation of the building envelope [12]. Further, it is more likely that homeowners adopt EEMs while they undertake home improvements [13]. Incorporating EEMs in renovation could transform a non-energy renovation to an energy renovation (ER) [13]. However, an EEM as a standalone measure, which is not undertaken as part of a major renovation, is not considered an ER. The level of energy efficiency achieved by an ER depends on the type and the quantity of EEMs included in the renovation package [14].

The research on investment decisions to improve single-family houses' energy efficiency by renovation has gained momentum in the last few decades [14-16]. The majority of studies in this area investigate the factors influencing the implementation of ER similar to a single measure $[17,18]$. This approach does not consider the differences in preferences and consequences between EEMs that are included in ER. Though homeowners, who implement ER, usually adopt EEMs in a package of measures [13], they may still evaluate each EEM separately, while adopting one individual EEM may affect the decision to adopt the others [16]. Homeowners' decision to adopt ER may depend on a combination of factors (context) such as adopter's socio-demographic aspects and house characteristics. Viewing ER as a single measure while neglecting the facilitating and/or impeding contexts of EEMs may give an incomplete perspective on enhancing the energy-saving by ER [16]. EEMs, as parts of ER affect the residents, the building, and each other [16,19]. However, studies focusing on specific EEMs miss the interplays between the measures. Such studies have different designs, and their results are difficult to be compared and generalized for ER implementation [20]. Without understanding the differences and similarities of the required context for adopting various EEMs, it would be challenging to devise strategies that promote ERs with multiple EEMs. Comparing the contexts of the adoption of various EEMs could provide insights on their similarities and differences that could facilitate the bundling of various EEMs to achieve enhanced energy savings by ER.

The objective of this study is to explore how the adoption of EEMs are influenced by their contexts, which consist of a set of "personal" and "house-related" factors. A comparative approach is used in this study to shed light on the relations between the contexts facilitating or impeding the adoption of the investigated EEMs. The data on the perceptions of owners of single-family houses is collected from a questionnaire survey. The homeowners' perceptions of different EEMs are comparatively analyzed with the inferential statistical method of chi-square test to unfold the contexts that facilitate or impede their adoption in the cold climate of northern Sweden.

\section{Adoption of EEMs in Single-Family Houses}

\subsection{Common EEMs Adopted in Single-Family Houses}

EEMs can be broadly defined as the measures that lead to an increase in the ratio of a process's useful output to its input energy [21]. EEMs might be adopted due to reasons other than saving energy; however, they would eventually lead to energy efficiency [22]. The overall energy demand in the Swedish residential sector consists of $70 \%$ space heating, $10 \%$ domestic hot water, and $20 \%$ electricity for lighting and appliances [8]. Accordingly, space-heating provides the highest opportunity for energy 
use reduction. EEMs are categorized into three groups based on their efficacy, including (i) thermal envelope, (ii) mechanical installations, and (iii) renewable energy sources [23].

A study that investigated some of the common EEMs in Swedish residential buildings states that improved insulation of the thermal envelope of buildings to decrease heat loss is a basic strategy to improve energy efficiency [8]. Improvement in the insulation of external walls and attics and replacing windows with more energy-efficient ones are three thermal envelope measures evaluated in this study. A study in Denmark implies these three are the most effective measures for reducing space heating in multi-family buildings [23]. Swedish homeowners were found to perceive attic insulation as the most energy cost-saving thermal envelope measure, although homeowners are more likely to replace windows [24]. One reason mentioned for their preference is the higher observability of windows than attic insulation [24].

Installing heat pump and ventilation system with heat recovery are two EEMs related to heating, ventilation, and air-conditioning (HVAC). A ventilation system with heat recovery can be adopted for the benefits such as improving air quality or/and energy efficiency. The specific barriers such as noise generation, negative pressure, and concerns about aesthetical aspects might inhibit the adoption of this EEM if they are not addressed with enhanced system design [23]. Heat pump is considered an environmentally friendly technology that enables the use of renewable energies [25]. A study in Norway, with a similar climate to Sweden, showed that air-source heat pump is the most common measure for energy upgrades [26]. A study in Finland infers ground-source heat pumps to be more cost-effective for emission reduction than other heating systems [14]. In this study, the homeowners' interests to install both air and ground source heat pumps are grouped together. The measures investigated in this study are also presented in a review by [16] as common measures to improve households' energy efficiency.

\subsection{The Influential Factors on the Adoption of EEMs}

Early studies on investments in households' energy efficiency deemed ER as a rational decision from a technical and economic perspective [27]. The importance of the economic viability of ER is asserted by several studies in the literature [22,28]. The low rate of adoption of EEMs despite their potential has led the researchers to identify barriers impeding the adoption [29]. Besides, studies have raised the need to look beyond techno-economic aspects by contextualizing ER in different disciplines, including socio-behavioral theories [30,31]. For example, a social marketing perspective can be utilized to view how the trade-off between the benefits and barriers of ER can influence different groups of homeowners to implement ER [32]. Diffusion of innovation is another approach introduced by [33], which can explain the dynamic of adopting EEMs in the renovation of single-family houses [24]. In this approach, the variables influencing the actors' decision to adopt an innovation can be grouped in various ways, such as innovators' characteristics, innovation characteristics, and the environmental context [33]. Recent studies gave relatively more emphasis on the importance of the human dimension of ER along with techno-economic aspects [34]. As stated by [35], buildings have a performative role in renovation decisions as they carry meaning, values, habits, and behavioral preferences. Hence it is important to pay attention to buildings' characteristics and residents' interactions with them.

Accordingly, several studies in the literature investigated the influence of human-related and building-related factors on the implementation of ER. A study in Sweden examined a set of factors categorized as "personal" and contextual factors that may influence the Swedish homeowners to implement ER [36]. "Personal" factors consist of demographics, skills, knowledge, and attitude of homeowners, while contextual factors are related to building such as age, thermal comfort, perceived energy cost, and past investment. A study in Germany adopted a similar approach, although investigated more factors related to lifestyle and occasions [37]. The relations of these factors with the benefits and barriers of ER is investigated by [32]. They inferred that the characteristics of adopters (personal factors) and buildings affect the perceived benefits and barriers and thereby eventually influence the implementation of ER. 
Based on the review of the studies mentioned earlier, a combination of important "personal" and "house-related" factors are identified and presented in Figure 1. The approach to examine the influence of such factors has already been employed for both ER and individual EEMs [16]. However, the comparative analysis of the contexts for different EEMs can reveal the relations between the required contexts for the collective adoption of EEMs. It can be assumed that the EEMs resembling each other in their functions (e.g., thermal envelope or HVAC) are likely to share similar influential factors for adoption. Since such EEMs may share the context facilitating their adoption, it is possible to adopt them together. However, it may be more challenging to adopt EEMs which do not share similar influential factors jointly.

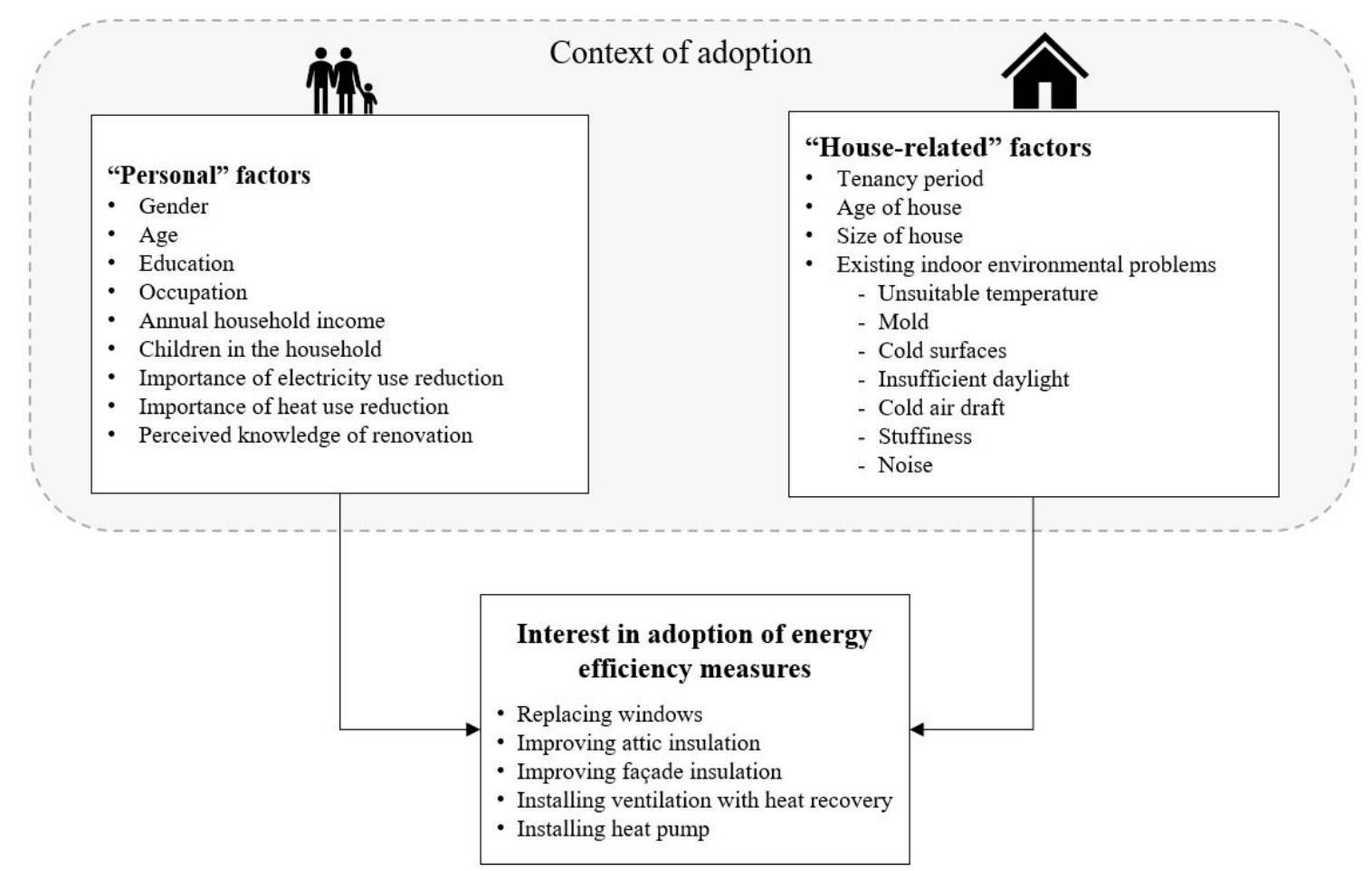

Figure 1. Schematic representation of the role of context on the adoption of energy efficiency measures.

\section{Methods}

The analysis is based on empirical data from a questionnaire survey of single-family homeowners. The important EEMs were identified from the literature review, and their local relevance was verified by interviewing a municipality energy advisor, who provides advice on energy use to homeowners in the region. The questionnaire consisted of four sections: (i) respondents' demographics, (ii) characteristics of their houses, (iii) respondents' knowledge and attitudes towards renovation, and (iv) respondents' perception of information sources for energy renovation. The questionnaire was pilot tested by eight homeowners. Their comments led to changes in the formulation of some of the questions to improve the relevance and clarity of the questions. In this study, a part of the questionnaire that covered the context of the adoption of EEMs (Figure 1) is used.

These questions on homeowners' attitudes related to electricity and heat use reduction were asked on a 5-point Likert scale. For example, "How important is it for you to reduce your household heating energy use?" was asked to understand respondents' attitudes to reduce household heating energy use. Respondents answered the question on a 5-point Likert scale $(1=$ not important at all, $5=$ highly important). For the analysis, we reclassified the 5-point responses related to homeowners' attitude to reduce energy use into three by grouping the options 4-5 as "important" and options 1-2 as "not important," while option 3 was the neutral option, which was "neither-nor." 
Studies have suggested that homeowners' knowledge plays an important role on the implementation of ER [38]. However, knowledge of ER consists of various aspects, such as knowledge on products and materials, costs, services offered by contractors, energy efficiency improvement, available financial incentives, and effect of renovation on the market value of the house. Accordingly, these six aspects were asked in the questionnaire wherein the respondents expressed their knowledge on each of these six aspects on a 5 -point Likert scale $(1=$ no knowledge, $5=$ in-depth knowledge). The responses to these 6 aspects were averaged to create a single variable, "knowledge of renovation."

The homeowners' interests in the adoption of specific EEMs (Figure 1) were investigated using the question "How interested are you to adopt these measures if you undertake a renovation in your house?" Similar to the questions related to "personal factors," the respondents could give their responses on a 5-point Likert scale. However, the focus of the analysis was on the group interested in adopting EEMs. Accordingly, the responses to this question were categorized into two groups: options 1-3 were categorized as "not interested/neither-nor" and options $4-5$ were categorized as "interested." This binary classification enhances the reliability of the statistical analysis of chi-square tests by increasing the number of counts in cross-tabulation $[39,40]$.

To investigate homeowners' experiences with indoor environmental problems (IEPs), the respondents were asked to state if they have issues with seven different IEPs in their houses. The investigated IEPs included unsuitable temperature, mold, cold surface, insufficient daylight, cold air draft, and stuffiness (insufficient ventilation). These IEPs were chosen from the literature to represent different aspects of indoor environmental quality [41,42]. Similar to the questions related to EEMs, the local relevance of IEPs was verified in an interview with the municipality energy advisor. The respondents who mentioned having at least one of the seven investigated IEPs were assigned to a new variable named IEP.

The questionnaires were sent by mail to 1550 owners of single-family houses during spring 2017. The addresses were collected from Statens person addresses register (SPAR), which is a public organization working with address registration in Sweden. The addresses were randomly selected from seven municipalities in the counties of Västerbotten and Norrbotten in northern Sweden. Accordingly, the sample group consisted of individuals irrespective of their experiences or intention of house renovation. The respondents were given the option to respond online instead of responding on a paper questionnaire, and $7.5 \%$ of received responses were online. The final response rate after a reminder was $29 \%$. There was a fairly even representation of male and female respondents and household income was normally distributed in our sample. The majority of respondents were above 55 years old, which complies with an earlier survey of Swedish households [31]. The percentages of respondents with different levels of education were closely related to the Swedish national levels except for the group with university education equal to or higher than 3 years. This group was over-represented with $35 \%$ as compared to $23 \%$ on the national level [37]. The percentage of responses to the questions related to "personal" factors and "house-related" factors are presented in Table 1.

Homeowners' responses to various questions related to context are statistically tested to find their relations with homeowners' interest to adopt different EEMs. The inferential statistical analysis was conducted by Pearson's chi-square test, which examines whether the observed distribution is due to chance and fits the expected frequencies [43]. A significant difference between observed and expected frequencies implies the association of variables. Otherwise, the tested variables can be inferred being independent of each other. Such analysis requires a contingency table consisting of $\mathrm{R}$ number of rows and C number of columns, which R and C represent the "levels" of the two tested variables. 
Table 1. Summary statistics of responses to the questionnaire.

\begin{tabular}{|c|c|c|c|}
\hline Factors Related to the Context of Adoption & Percentage of Respondents & Factors Related to the Context of Adoption & Percentage of Respondents \\
\hline Gender $(N=451)$ & & Children below 18 years old $(\mathrm{N}=423)$ & \\
\hline Male & $55 \%$ & Yes & $71 \%$ \\
\hline Female & $45 \%$ & No & $29 \%$ \\
\hline Age $(N=443)$ & & Annual income (1000 SEK *), $(\mathrm{N}=432)$ & \\
\hline $18-45$ & $22 \%$ & $<350$ & $15 \%$ \\
\hline $46-55$ & $19 \%$ & $350-500$ & $22 \%$ \\
\hline $56-65$ & $24 \%$ & $501-750$ & $32 \%$ \\
\hline \multirow[t]{2}{*}{$65<$} & $35 \%$ & $751-900$ & $19 \%$ \\
\hline & & $900<$ & $12 \%$ \\
\hline \multicolumn{4}{|l|}{ Occupation $(N=434)$} \\
\hline Paid work, full time & $53 \%$ & Tenancy period (year) $(\mathrm{N}=440)$ & \\
\hline part time, unemployed & $8 \%$ & $1-3$ & $9 \%$ \\
\hline \multirow{2}{*}{ Pensioner } & $39 \%$ & $4-10$ & $19 \%$ \\
\hline & & $11-20$ & $24 \%$ \\
\hline Highest education $(\mathrm{N}=437)$ & & $21-30$ & $18 \%$ \\
\hline Elementary/middle school & $11 \%$ & $31-40$ & $19 \%$ \\
\hline High school & $41 \%$ & $>40$ & $10 \%$ \\
\hline University $<3$ years & $12 \%$ & & \\
\hline \multirow[t]{2}{*}{ University $\geq 3$ years } & $35 \%$ & Age of house (year) $(\mathrm{N}=439)$ & \\
\hline & & $<25$ & $8 \%$ \\
\hline \multirow{2}{*}{ Perceived knowledge of renovation $(\mathrm{N}=439)$} & & $25-40$ & $22 \%$ \\
\hline & & $41-55$ & $30 \%$ \\
\hline Low & $19 \%$ & $56-70$ & $20 \%$ \\
\hline Average & $48 \%$ & $70<$ & $20 \%$ \\
\hline \multirow[t]{2}{*}{ High } & $33 \%$ & & \\
\hline & & Size $\left(m^{2}\right)(N=428)$ & \\
\hline Importance of reducing electricity use $(\mathrm{N}=$ & & $<100$ & $13 \%$ \\
\hline 417) & & $100-150$ & $52 \%$ \\
\hline Not important & $24 \%$ & $151-200$ & $25 \%$ \\
\hline Neither-nor & $26 \%$ & $>200$ & $10 \%$ \\
\hline \multirow[b]{2}{*}{ 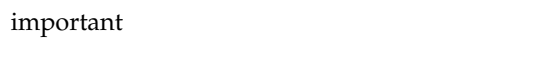 } & $50 \%$ & & \\
\hline & & Indoor environmental problems $(\mathrm{N}=451)$ & \\
\hline \multirow{2}{*}{ Importance of reducing heat use $(\mathrm{N}=328)$} & & Unsuitable temperature & $7.3 \%$ \\
\hline & & Mold & $0.4 \%$ \\
\hline Not important & $25 \%$ & Cold surfaces & $26.4 \%$ \\
\hline Neither-nor & $26 \%$ & Insufficient daylight & $2.2 \%$ \\
\hline \multirow[t]{4}{*}{ Important } & $49 \%$ & Cold air draft & $6 \%$ \\
\hline & & Stuffiness & $12 \%$ \\
\hline & & Noise from outside & $5 \%$ \\
\hline & & IEP & $46 \%$ \\
\hline
\end{tabular}

$\mathrm{N}$ refers to the number of valid responses. ${ }^{*} 1$ Euro $\approx 10.2$ SEK (18 November 2020$)$. 
Additional post-hoc analysis was conducted for all the statistically significant findings of the chi-square tests. The post-hoc analysis provides further explanations on the significant relations between variables tested by the chi-square. The chi-square test shows the overall statistically significant results, while the post-hoc analysis uses adjusted residuals to indicate where the significances are embedded in the contingency table $[39,44]$. This method can reveal which groups in the related variables contribute to the significance of a relation (showed by chi-square test). The adjusted residuals higher than 1.96 and lower than -1.96 are significant with $p \leq 0.05$. The analysis methods for chi-square test and post-hoc analysis were carried out using the statistical package of SPSS.

\section{Results and Discussion}

The respondents' interests in adopting different EEMs if they renovate their houses were analyzed and the EEMs are presented in Figure 2. Approximately $60 \%$ of respondents expressed interest in adopting one or more of the investigated EEMs. Replacing windows and installing heat pumps are the EEMS with the highest interest, with $29 \%$ and $26 \%$ of respondents interested in adopting them, respectively. On the other hand, improving façade insulation with about $15 \%$ received the least interest among the investigated EEMs. The results show $43 \%$ and $36 \%$ of respondents were interested in at least one EEM related to thermal envelope and HVAC measures, respectively.

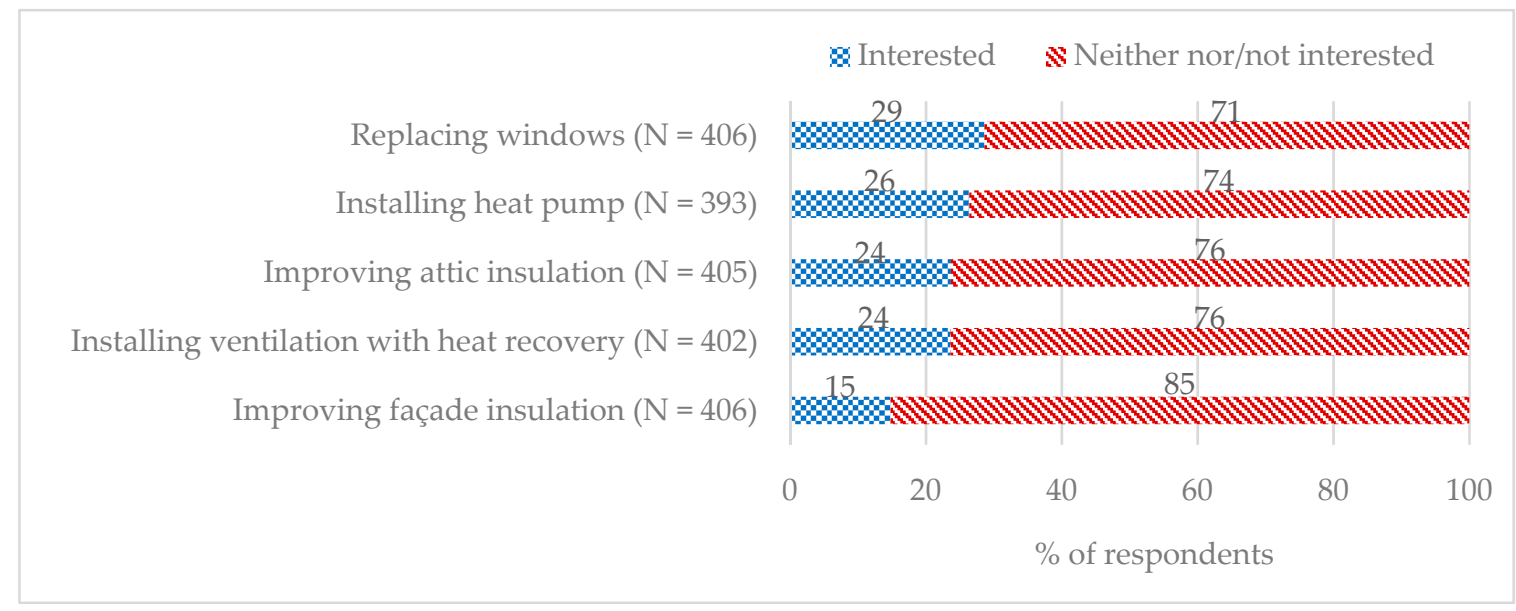

Figure 2. The interest of homeowners in adopting different energy efficiency measures (EEMs).

In the following sections, the results of chi-square tests are presented along with the discussions on findings from post-hoc analyses when chi-square tests are significant. The results of post-hoc analysis are provided in Appendix A at the end of this paper. The tables in Appendix A present the adjusted residuals from chi-square tests to show the significance of different groups in the variables.

\section{1. "Personal" Factors}

Gender and whether children (age $<18$ ) live in the household are the factors found to be significantly associated with improving attic insulation (Table 2). The post-hoc analysis of chi-square results reveals the details on the association of gender and improving attic insulation (Table A2 in Appendix A). Male homeowners, as compared to females, are significantly more likely to show interest in improving attic insulation. Gender affects people's needs and the use of energy, and the way everyday-life is impacted by energy conservations [45]. Homeowners who do not have any children living in their households are more likely to be interested in improving attic insulation. Avoiding exposing children to the risk of respiratory issues caused by this EEM might be one reason discouraging the homeowners who have children to adopt this EEM [46]. 
Table 2. Influence of "personal" factors on homeowners' interest to adopt EEMs.

\begin{tabular}{cccccc}
\hline & \multicolumn{5}{c}{ Probability Value $(p)$} \\
\cline { 2 - 6 } “Personal” Factors & $\begin{array}{c}\text { Replacing } \\
\text { Windows }\end{array}$ & $\begin{array}{c}\text { Installing } \\
\text { Heat Pump }\end{array}$ & $\begin{array}{c}\text { Improving } \\
\text { Attic } \\
\text { Insulation }\end{array}$ & $\begin{array}{c}\text { Installing } \\
\text { Ventilation } \\
\text { with Heat } \\
\text { Recovery }\end{array}$ & $\begin{array}{c}\text { Improving } \\
\text { Façade } \\
\text { Insulation }\end{array}$ \\
\hline Gender & 0.49 & 0.91 & 0.03 & 0.47 & 0.69 \\
Age & 0.25 & 0.68 & 0.52 & 0.82 & 0.99 \\
Education & 0.10 & 0.07 & 0.08 & 0.90 & 0.15 \\
Occupation & 0.24 & 0.27 & 0.16 & 0.76 & 0.06 \\
Annual household income & 0.11 & 0.54 & 0.16 & 0.42 & 0.61 \\
Children in household & 0.15 & 0.32 & 0.03 & 0.27 & 0.21 \\
Knowledge of renovation & 0.14 & 0.03 & 0.56 & 0.40 & 0.95 \\
Importance of reducing el. use & 0.02 & 0.04 & 0.22 & 0.58 & 0.00 \\
Importance of reducing heat use & 0.01 & 0.20 & 0.00 & 0.18 & 0.00 \\
\hline
\end{tabular}

Significant results of chi-square tests are highlighted when $p \leq 0.05$.

As shown in Table 2, perceived knowledge of renovation was found to have a significant association with installing heat pump while the relations between knowledge and the interest to adopt other EEMs are insignificant. The negative effect of lack of knowledge and expertise on the adoption of heat pump is also found and discussed by other studies [38].

The perceived importance of reducing energy use is shown in another study to affect homeowners' decisions to improve the thermal envelope of their houses [24]. In this analysis, the homeowners' perception of the importance of reducing their electricity and heat use were asked separately. The results of chi-square tests presented in Table 2 show significant relations between the homeowners' interest in replacing windows and improving façade insulation with the perceived importance of reducing both electricity and heat use. The interest to improve attic insulation is more likely among the homeowners who perceive it important to reduce their heat use (Table 2). The interest to adopt heat pump is more likely among those who think it is important to reduce electricity use. This may be partly attributed to some of those households that use electricity for heating.

\section{2. "House-Related" Factors}

The factors related to houses, such as age and tenancy periods, are found to have significant relations with the EEMs in the thermal envelope category (Table 3). However, the size of the house does not have any significant relation with the investigated EEMs. Post-hoc analysis presented in Table A2 (in Appendix A) shows that the homeowners who recently moved in to their houses ( $\leq 3$ years) are more likely to be interested in improving attic insulation. After this period, until ten years from their tenancy, it is less likely that they are interested in adopting this EEM. These results might indicate homeowners' reluctance to be distracted from their daily routine that might be caused by the adoption process [32,47]. Measures such as window replacement may not cause much disturbances to the everyday life of occupants. Homeowners may decide to replace their windows anytime, as a piece-meal approach, when they perceive the windows as old and in poor condition [48]. On the other hand, improving attic insulation might require more effort to organize, besides the hassle of clean-up and the risk of respiratory and health distress [46]. Thus, the homeowners might prefer to adopt this EEM in the early stages when they buy the house, before or during the move-in process. 
Table 3. Influence of "house-related" factors on homeowners' interest to adopt EEMs.

\begin{tabular}{cccccc}
\hline \multirow{2}{*}{$\begin{array}{c}\text { Fouse-Related" } \\
\text { Factors }\end{array}$} & $\begin{array}{c}\text { Replacing } \\
\text { Windows }\end{array}$ & $\begin{array}{c}\text { Installing } \\
\text { Heat Pump }\end{array}$ & $\begin{array}{c}\text { Improving } \\
\text { Attic } \\
\text { Insulation }\end{array}$ & $\begin{array}{c}\text { Installing Ventilation } \\
\text { with Heat Recovery }\end{array}$ & $\begin{array}{c}\text { Improving } \\
\text { Façade } \\
\text { Insulation }\end{array}$ \\
\hline Tenancy period & 0.31 & 0.84 & 0.02 & 0.67 & 0.82 \\
Age of house & 0.00 & 0.47 & 0.05 & 0.03 & 0.43 \\
Size of house & 0.77 & 0.98 & 0.41 & 0.93 & 0.06 \\
IEP & 0.05 & 0.31 & 0.00 & 0.00 & 0.00 \\
\hline
\end{tabular}

Significant results of chi-square tests are highlighted when $p \leq 0.05$.

In Table 3, the age of houses is shown to have significant relations with several EEMs, including replacing windows, improving attic insulation, and installing ventilation system with heat recovery. Window replacement is less likely to be adopted by homeowners in the houses that were built within 25 years (Table A1 in Appendix A), which complies with the previous findings [48]. Similar results are found on homeowners' interest in improving attic insulation (Table A2 in Appendix A). On the other hand, homeowners living in houses older than 70 years are unlikely to install ventilation with heat recovery (Table A3 in Appendix A). The building design in such old houses may cause it to be technically demanding to adopt the EEMs, which require building modifications.

IEPs are frequently identified as important drivers for the homeowners to implement ER [32,49]. As shown in Table 1, 46\% of respondents stated that their house has at least one IEP. Table 3 shows the associations between the interest to adopt EEMs and IEPs. Several EEMs, except installing heat pump, are found to have significant associations with the variable IEP. The adoption of heat pump is seemingly independent of the quality of the indoor environment.

The significant influence of IEPs on the homeowners' interest to adopt EEMs indicates the necessity of conducting a detailed analysis of IEPs. The results presented in Table 4 show the majority of investigated IEPs have significant relations with the homeowners' interest in adopting one or several EEMs. IEPs, such as unsuitable temperature and insufficient daylight, may not influence the interest of homeowners to adopt any of the investigated EEMs.

Table 4. Influence of indoor environmental problems on the interest to adopt EEMs.

\begin{tabular}{ccccc}
\hline \multirow{2}{*}{$\begin{array}{c}\text { Indoor Environmental } \\
\text { Problems (IEPs) }\end{array}$} & $\begin{array}{c}\text { Probability Value }(p) \\
\text { Replacing } \\
\text { Windows }\end{array}$ & $\begin{array}{c}\text { Improving Attic } \\
\text { Insulation }\end{array}$ & $\begin{array}{c}\text { Installing } \\
\text { Ventilation with } \\
\text { Heat Recovery }\end{array}$ & $\begin{array}{c}\text { Improving Façade } \\
\text { Insulation }\end{array}$ \\
\hline Unsuitable temperature & 0.54 & 0.38 & 0.18 & 0.39 \\
Cold surfaces & 0.28 & 0.00 & 0.00 & 0.00 \\
Cold air draft & 0.01 & 0.09 & 0.01 & 0.01 \\
Stuffiness & 0.38 & 0.16 & 0.00 & 0.97 \\
Mold & 0.40 & 0.01 & 0.01 & 0.13 \\
Insufficient daylight & 0.30 & 0.50 & 0.93 & 0.12 \\
Noise & 0.00 & 0.11 & 0.54 & 0.01 \\
\hline
\end{tabular}

Significant results of chi-square tests are highlighted when $p \leq 0.05$.

Post-hoc analyses of chi-square results are conducted to reveal more details of the relations between the interest to adopt different EEMs and the IEPs in the houses. The EEM, installing heat pump is excluded from Table 4 as it does not have any significant relation with the variable IEP. The homeowners who stated to have IEPs in their houses are more likely to adopt at least one thermal envelope measure. The IEPs, which have significant relations with the adoption of thermal envelope measures, are cold surfaces, cold air draft, noise from outside, and mold. The interest to replace windows is found to be related to cold air draft and noise from outside. A similar analysis for improvement of attic insulation shows the homeowners' interest is significantly related to the problems of mold and cold surfaces. The interest in improving façade insulation was significantly related to the problems of cold surface, cold air draft, and noise from outside. In addition to the thermal envelope measures, 
installing ventilation with heat recovery, which is an HVAC measure, is found to have significant relations with several IEPs, including mold, cold surfaces, cold air draft, and stuffiness. Several IEPs are found to have significant associations with the adoption of multiple EEMs. Accordingly, IEPs could be important drivers for energy efficiency improvement as they provide the opportunity to bundle several EEMs together to enhance the energy-saving effect of ER.

The statistical tests on mold have less reliability since only a small group of homeowners reported this problem. Nevertheless, all homeowners in our sample who had this problem expressed interest in improving attic insulation and to install ventilation with heat recovery, which suggests this IEP can trigger the adoption of those EEMs.

\section{General Remarks and Policy Implications}

Energy decisions in the residential sector are complex and diverse, as they are influenced by a wide range of psychological and contextual factors [50]. The energy reduction potential of ER depends on the type and number of EEMs incorporated in a renovation. EEMs can be adopted individually or collectively based on different contexts that facilitate their adoption. The results of this study show that individual EEMs are influenced differently by a diverse set of "personal" and "house-related" factors. Accordingly, viewing ER without considering the factors that influence the adoptions of various EEMs may be inadequate to facilitate significant energy reduction. To increase the energy savings, policy efforts should facilitate bundling as many EEMs as possible when homeowners decide on ER.

Homeowners' perceptions and attitudes on energy use and their knowledge of renovation are more likely to be significant for adopting EEMs compared to demographic factors. The demographic factors are found to play a role in improving attic insulation, which has a more demanding adoption process in terms of time, hassles, and disruptions to everyday-life [46,47]. This indicates the specific need to utilize psychological and behavioral approaches to understand the underlying barriers towards adopting this EEM.

The analysis shows similar influential factors for several EEMs, such as those in the thermal envelope category. For example, the perceived importance of heat use reduction and IEPs can influence the adoption of all three thermal envelope EEMs. This has implications for improving façade insulation, which is an EEM that homeowners are less likely to adopt (Figure 2). For example, the contexts conducive to replacing windows can also be leveraged to improve façade insulation.

Comparing the two investigated EEMs in the category of HVAC measures shows the contexts that influence the interest in their adoption are different, which may indicate their differences, such as in functions and applications. Installing heat pump has significant associations with "personal" factors, while installingventilation system with heat recovery has significant relations with house-related factors. Increasing the adoption rate of these measures, together within an ER package, may require special attention on devising tailored policies and marketing strategies.

The results have implications for the design and modification of policies facilitating the adoption of EEMs for renovations of single-family houses. IEPs provide a context that may facilitate the adoption of several EEMs. A large percentage of respondents (46\%) stated to have at least one IEP in their houses, and $70 \%$ in that group were interested in adopting the minimum of one EEM. Improving occupants' comfort and well-being should be given more attention in policy-making, as research suggests that energy cost savings may not be the driving force for homeowners to implement ER [32]. Similarly, the positive influence of environmental awareness on the implementation of ER is disputed by some research studies [18]. Information campaigns introducing EEMs as solution for IEPs to improve comfort and health may facilitate the adoption of EEMs by households experiencing IEPs. Moreover, Energy Performance Certificate (EPC), mandated by EPBD in Europe [6], can be utilized to provide information on a building's comfort level besides the primary purpose of presenting energy performance. EPC could become a long-term road map for adoption of EEMs by merging various adoption motives, including improvement in the energy performance and comfort level of a house, to enable more EEMs being bundled together in ER implementation. 
The homeowners with higher perceived knowledge on renovation showed more interest in adopting heat pumps. Though heat pump is a mature technology and the products are widely available in the Swedish market, the homeowners might envision it as complex and technically demanding to adopt. Providing reliable information on the potential energy saving of different EEMs could be one way to create interest in such measures among homeowners. A study in Germany underlined the importance of unbiased information sources as they found low trust and acceptance of advice from professionals in the commercial sector [18]. Publicly funded online tools that can provide tailored calculations on cost-saving potentials could stimulate interest in these EEMs. Such initiatives are consistent with the European legislation by EED, which demands that member states "... promote suitable information, awareness-raising and training initiatives to inform citizens of the benefits and practicalities of taking energy efficiency improvement measures" [5]. However, it might be challenging to provide detailed and tailored technical information by online tools which at the same time need to be user-friendly. Further, marketing strategies may be required to resolve the perceived complexity for the adoption and operation of EEMs, such as heat pumps. The findings can be utilized by actors such as installers and material suppliers who have a notable influence on Swedish homeowners' adoption decisions [51]. Such actors can use the findings to devise targeted marketing strategies promoting the EEMs to the potential group of adopters by considering their contexts.

\section{Conclusions}

This empirical study examines a set of factors that may influence homeowners' interest in adopting EEMs. Our study shows that EEMs are influenced differently by the context of adoption. It is important to include several EEMs within renovation packages to increase their energy-saving effect. The policies should facilitate the simultaneous adoption of several EEMs when homeowners intend to implement renovation. The comparative analysis evaluates the contexts for adopting individual EEMs and differentiate the factors between EEMs. This approach could enable identifying the interlinkages such as (in)compatibilities and shared opportunities, thereby suggesting which EEMs can better fit together when homeowners plan to implement ER. The results can serve as a basis to formulate suitable policies for each of the EEMs or a combination of EEMs in a renovation package. Moreover, this approach can contribute to the explanation of the reasons for the relatively higher adoption rate of specific EEMs.

The EEMs are investigated regardless of their benefits or barriers perceived by the homeowners. Instead, the underlying "personal" and "house-related" factors that might shape the homeowners' perceptions of the benefits and barriers of adopting EEMs are considered for the analysis. This strategy is useful to highlight the contexts, leading to an increase in the adoption rate of different EEMs. However, a comparative analysis cannot replace the in-depth analysis required for individual EEM to understand more specific contexts, drivers, and barriers.

This study is limited to the most frequently-used factors and energy efficiency measures found in the literature. Future studies may include more EEMs and influential factors to establish a profound understanding of the relations between the adoption of different EEMs that may be incorporated in an ER package. IEPs are considered building characteristics in the analysis, while their extensive influence on EEMs' adoption decisions indicates homeowners' motives to improve their comfort. However, without examining the perceived benefits and barriers driving the homeowners' decisions, the results might have limited implications for causal relations of contexts and homeowners' adoption decisions. Further studies should examine the intermediary influence of perceived benefits and barriers to better understand the causal relations of the influential factors and the adoption of EEMs. Such studies may take into account the energy effectiveness of ER when various EEMs are bundled together in a renovation package. 
Author Contributions: Conceptualization, S.A., G.N. and T.O.; methodology, S.A., G.N. and T.O.; software, S.A. and G.N.; formal analysis, S.A.; investigation S.A.; resources, G.N., T.O.; data curation, S.A.; writing-original draft preparation, S.A.; writing—review and editing, G.N., T.O.; visualization, S.A.; supervision, G.N., T.O.; project administration, T.O., G.N.; funding acquisition, T.O. All authors have read and agreed to the published version of the manuscript.

Funding: This study is financially supported by the European Union under Interreg Botnia-Atlantica program titled Renovation Centre with grant number 303-5806-2015.

Conflicts of Interest: The authors declare no conflict of interest. The funders had no role in the design of the study; in the collection, analyses, or interpretation of data; in the writing of the manuscript, or in the decision to publish the results.

\section{Appendix A. Post-Hoc Analysis of Significant Chi-Square Results}

Table A1. Post-hoc analyses of influential factors on homeowners' interest to replace windows.

\begin{tabular}{llcc}
\hline \multirow{2}{*}{$\begin{array}{l}\text { Influential Factors } \\
\end{array}$} & & \multicolumn{2}{c}{ Adjusted Residuals; Replacing Windows } \\
\cline { 3 - 4 } & & $\begin{array}{c}\text { Not interested/ } \\
\text { Neither-Nor }\end{array}$ & Interested \\
\hline \multirow{2}{*}{ Importance of reducing electricity use } & Not important & 2.5 & -2.5 \\
& Neither nor & -2 & 2 \\
& Important & -0.4 & 0.4 \\
\hline \multirow{2}{*}{ Importance of reducing heat use } & Not important & 2.8 & -2.8 \\
& Neither nor & -2.3 & 2.3 \\
& Important & -0.4 & 0.4 \\
\multirow{3}{*}{ Age of house } & $<25$ & 3.5 & -3.5 \\
(years) & $26-40$ & -1.4 & 1.4 \\
& $41-55$ & -1.8 & 1.8 \\
\hline \multirow{2}{*}{ IEP } & $56-70$ & 0.8 & -0.8 \\
\hline \multirow{2}{*}{ Cold air draft } & $70<$ & 0.4 & -0.4 \\
\hline \multirow{2}{*}{ Noise from outside } & Yes & -1.97 & 1.97 \\
& No & 1.97 & -1.97 \\
\hline
\end{tabular}

Adjusted residuals higher than 1.96 and lower than -1.96 are significant with $p \leq 0.05$. Adjusted residuals higher than 1.96 highlighted with blue show significant likelihood and those lower than -1.96 highlighted with orange show significant unlikelihood.

Table A2. Post-hoc analyses of influential factors on homeowners' interest to improve attic insulation.

\begin{tabular}{|c|c|c|c|}
\hline \multicolumn{2}{|c|}{ Influential Factors } & \multicolumn{2}{|c|}{ Adjusted Residuals; Improving Attic Insulation } \\
\hline Influential Fact & & $\begin{array}{l}\text { Not Interested/ } \\
\text { Neither-Nor }\end{array}$ & Interested \\
\hline \multirow{2}{*}{ Gender } & \multirow{2}{*}{$\begin{array}{l}\text { Female } \\
\text { Male }\end{array}$} & 2.2 & -2.2 \\
\hline & & -2.2 & 2.2 \\
\hline \multirow{2}{*}{ Children below 18 years old } & Yes & 2.2 & -2.2 \\
\hline & No & -2.2 & 2.2 \\
\hline \multirow{3}{*}{ Importance of reducing heat use } & Not important & 0.8 & -0.8 \\
\hline & Neither-nor & 2.8 & -2.8 \\
\hline & Important & -3.2 & 3.2 \\
\hline \multirow{6}{*}{ Tenancy period (years) } & $1-3$ & -2.7 & 2.7 \\
\hline & $4-10$ & 2 & -2 \\
\hline & $11-20$ & -1.2 & 1.2 \\
\hline & $21-30$ & 0.4 & -0.4 \\
\hline & $31-40$ & -0.2 & 0.2 \\
\hline & $>40$ & 1.5 & -1.5 \\
\hline
\end{tabular}


Table A2. Cont.

\begin{tabular}{|c|c|c|c|}
\hline \multirow{2}{*}{\multicolumn{2}{|c|}{ Influential Factors }} & \multicolumn{2}{|c|}{ Adjusted Residuals; Improving Attic Insulation } \\
\hline & & $\begin{array}{l}\text { Not Interested/ } \\
\text { Neither-Nor }\end{array}$ & Interested \\
\hline \multirow{5}{*}{$\begin{array}{l}\text { Age of house } \\
\text { (years) }\end{array}$} & $<25$ & 3.1 & -3.1 \\
\hline & $25-40$ & -0.3 & 0.3 \\
\hline & $41-55$ & -0.4 & 0.4 \\
\hline & $56-70$ & -0.4 & 0.4 \\
\hline & $70<$ & -0.8 & 0.8 \\
\hline \multirow{2}{*}{ IEP } & Yes & -3.2 & 3.2 \\
\hline & No & 3.2 & -3.2 \\
\hline \multirow{2}{*}{ Mold } & Yes & -2.7 & 2.7 \\
\hline & No & 2.7 & -2.7 \\
\hline \multirow{2}{*}{ Cold surfaces } & Yes & -3 & 3 \\
\hline & No & 3 & -3 \\
\hline
\end{tabular}

Adjusted residuals higher than 1.96 and lower than -1.96 are significant with $p \leq 0.05$. Adjusted residuals higher than 1.96 highlighted with blue show significant likelihood and those lower than -1.96 highlighted with orange show significant unlikelihood.

Table A3. Post-hoc analyses of influential factors on homeowners' interest to install ventilation with heat recovery.

\begin{tabular}{llcc}
\hline \multirow{2}{*}{ Influential Factors } & \multicolumn{2}{c}{ Adjusted Residuals; Installing Ventilation with Heat Recovery } \\
\cline { 3 - 4 } & & Not Interested/Neither-Nor & Interested \\
\hline \multirow{4}{*}{ Age of house } & $<25$ & 1.7 & -1.7 \\
\multirow{2}{*}{ years) } & $25-40$ & -1.8 & 1.8 \\
& $41-55$ & -0.5 & 0.5 \\
& $56-70$ & -1 & 1 \\
\hline \multirow{2}{*}{ IEP } & Yes & 2.3 & -2.3 \\
\hline \multirow{2}{*}{ Mold } & No & -5.2 & 5.2 \\
& Yes & 5.2 & -5.2 \\
\hline \multirow{2}{*}{ Cold surfaces } & No & -2.7 & 2.7 \\
& Yes & 2.7 & -2.7 \\
\hline \multirow{2}{*}{ Cold air draft } & No & -2.9 & 2.9 \\
& Yes & 2.9 & -2.9 \\
\hline \multirow{2}{*}{ Stuffiness } & No & -2.7 & 2.7 \\
& Yes & 2.7 & -2.7 \\
\hline
\end{tabular}

Adjusted residuals higher than 1.96 and lower than -1.96 are significant with $p \leq 0.05$. Adjusted residuals higher than 1.96 highlighted with blue show significant likelihood and those lower than -1.96 highlighted with orange show significant unlikelihood. 
Table A4. Post-hoc analyses of influential factors on homeowners' interest to improve facade insulation.

\begin{tabular}{|c|c|c|c|}
\hline \multirow{2}{*}{\multicolumn{2}{|c|}{ Influential Factors }} & \multicolumn{2}{|c|}{ Adjusted Residuals; Improving Façade Insulation } \\
\hline & & Not Interested/ & \\
\hline \multirow{3}{*}{$\begin{array}{l}\text { Importance of reducing } \\
\text { electricity use }\end{array}$} & Not important & 2.7 & -2.7 \\
\hline & Neither-nor & 1.7 & -1.7 \\
\hline & Important & -3.7 & 3.7 \\
\hline \multirow{3}{*}{ Importance of reducing heat use } & Not important & 1.9 & -1.9 \\
\hline & Neither-nor & 3.2 & -3.2 \\
\hline & Important & -4.4 & 4.4 \\
\hline \multirow{2}{*}{ IEP } & Yes & -3.3 & 3.3 \\
\hline & No & 3.3 & -3.3 \\
\hline \multirow{2}{*}{ Cold surfaces } & Yes & -4.8 & 4.8 \\
\hline & No & 4.8 & -4.8 \\
\hline
\end{tabular}

Adjusted residuals higher than 1.96 and lower than -1.96 are significant with $p \leq 0.05$. Adjusted residuals higher than 1.96 highlighted with blue show significant likelihood and those lower than -1.96 highlighted with orange show significant unlikelihood.

Table A5. Post-hoc analyses of influential factors on homeowners' interest to install heat pump.

\begin{tabular}{|c|c|c|c|}
\hline \multirow{2}{*}{\multicolumn{2}{|c|}{ Influential Factors }} & \multicolumn{2}{|c|}{ Adjusted Residuals; Installing Heat Pump } \\
\hline & & $\begin{array}{l}\text { Not Interested/ } \\
\text { Neither-Nor }\end{array}$ & Interested \\
\hline \multirow{3}{*}{$\begin{array}{l}\text { Perceived knowledge of } \\
\text { renovation }\end{array}$} & Low & 0.8 & -0.8 \\
\hline & Average & 1.9 & -1.9 \\
\hline & High & -2.7 & 2.7 \\
\hline \multirow{3}{*}{$\begin{array}{l}\text { Importance of reducing } \\
\text { electricity use }\end{array}$} & Not important & 1.3 & -1.3 \\
\hline & Neither-nor & 1.7 & -1.7 \\
\hline & Important & -2.6 & 2.6 \\
\hline
\end{tabular}

Adjusted residuals higher than 1.96 and lower than -1.96 are significant with $p \leq 0.05$. Adjusted residuals higher than 1.96 highlighted with blue show significant likelihood and those lower than -1.96 highlighted with orange show significant unlikelihood.

\section{References}

1. International Energy Agency. World Energy Balance Overview 2017; International Energy Agency: Paris, France, 2017.

2. International Energy Agency; United Nations Environment Programme. 2019 Global Status Report for Buildings and Construction; International Energy Agency: Paris, France, 2019; ISBN 9789280737684.

3. Artola, I.; Rademaekers, K.; Williams, R.; Yearwood, J. Boosting Building Renovation: What Potential and Value for Europe? Study for the ITRE Committee. Available online: https://www.europarl.europa.eu/ RegData/etudes/STUD/2016/587326/IPOL_STU\%282016\%29587326_EN.pdf (accessed on 7 August 2020).

4. International Energy Agency. International Energy Outlook 2019 with Projections to 2050; International Energy Agency: Washington, DC, USA, 2019.

5. EU EED, Directive 2012/27/EU of the European Parliament and of the Council of 25 October 2012 on Energy Efficiency, Amending Directives 2009/125/EC and 2010/30/EU and Repealing Directives 2004/8/EC and 2006/32/EC. Available online: https://eur-lex.europa.eu/legal-content/EN/TXT/PDF/?uri=CELEX: 32012L0027\&from=EN (accessed on 7 August 2020).

6. EU EPBD, Directive 2010/31/EU of the European Parliament and of the Council of 19 May 2010 on the Energy Performance of Buildings. Available online: https:/eur-lex.europa.eu/legal-content/EN/TXT/PDF/?uri= CELEX:32010L0031\&from=EN (accessed on 7 August 2020).

7. Regeringskansliet. Sveriges Nationella Reformprogram 2014; Regeringskansliet: Stockholm, Sweden, 2014.

8. Mata, É.; Sasic Kalagasidis, A.; Johnsson, F. Energy usage and technical potential for energy saving measures in the Swedish residential building stock. Energy Policy 2013, 55, 404-414. [CrossRef]

9. Nair, G.; Azizi, S.; Olofsson, T. A management perspective on energy efficient renovations in Swedish multi-family buildings. Energy Procedia 2017, 132, 994-999. [CrossRef] 
10. Vilches, A.; Garcia-Martinez, A.; Sanchez-Montañes, B. Life cycle assessment (LCA) of building refurbishment: A literature review. Energy Build. 2017, 135, 286-301. [CrossRef]

11. Boverket. Beräkning av Behovet av Nya Bostäder till 2025, Rap-port 2017:17; Boverket: Karlskrona, Sweden, 2018.

12. Wilson, C.; Chrysochoidis, G.; Pettifor, H. Understanding Homeowners' Renovation Decisions: Findings of the VERD Project; UK Energy Research Centre (UKERC): London, UK, 2013.

13. Wilson, C.; Crane, L.; Chryssochoidis, G. Why do homeowners renovate energy efficiently? Contrasting perspectives and implications for policy. Energy Res. Soc. Sci. 2015, 7, 12-22. [CrossRef]

14. Hirvonen, J.; Jokisalo, J.; Heljo, J.; Kosonen, R. Towards the EU Emission Targets of 2050: Cost-Effective Emission Reduction in Finnish Detached Houses. Energies 2019, 12, 4395. [CrossRef]

15. Friege, J.; Chappin, E. Modelling decisions on energy-efficient renovations: A review. Renew. Sustain. Energy Rev. 2014, 39, 196-208. [CrossRef]

16. Kastner, I.; Stern, P.C. Examining the decision-making processes behind household energy investments: A review. Energy Res. Soc. Sci. 2015. [CrossRef]

17. Wilson, C.; Pettifor, H.; Chryssochoidis, G. Quantitative modelling of why and how homeowners decide to renovate energy efficiently. Appl. Energy 2018, 212, 1333-1344. [CrossRef]

18. Baumhof, R.; Decker, T.; Menrad, K. A comparative analysis of house owners in need of energy efficiency measures but with different intentions. Energies 2019, 12, 2267. [CrossRef]

19. Judson, E.P.; Maller, C. Housing renovations and energy efficiency: Insights from homeowners' practices. Build. Res. Inf. 2014, 42, 501-511. [CrossRef]

20. DeCanio, S.J.; Watkins, W.E. Investment in energy efficiency: Do the characteristics of firms matter? Rev. Econ. Stat. 1998, 80, 95-107. [CrossRef]

21. Patterson, M.G. What is energy efficiency? Concepts, indicators and methodological issues. Energy Policy 1996, 24, 377-390. [CrossRef]

22. Zundel, S.; Stieß, I. Beyond profitability of energy-saving measures-Attitudes towards energy saving. J. Consum. Policy 2011, 34, 91-105. [CrossRef]

23. Morelli, M.; Rønby, L.; Mikkelsen, S.E.; Minzari, M.G.; Kildemoes, T.; Tommerup, H.M. Energy retrofitting of a typical old Danish multi-family building to a "nearly-zero" energy building based on experiences from a test apartment. Energy Build. 2012, 54, 395-406. [CrossRef]

24. Nair, G.; Gustavsson, L.; Mahapatra, K. Owners perception on the adoption of building envelope energy efficiency measures in Swedish detached houses. Appl. Energy 2010, 87, 2411-2419. [CrossRef]

25. EU Parliament. EU Directive 2009/28/EC of the European Parliament and of the Council of 23 April 2009. Off. J. Eur. Union 2009, 140, 16-62. [CrossRef]

26. Risholt, B.; Berker, T. Success for energy efficient renovation of dwellings-Learning from private homeowners. Energy Policy 2013, 61, 1022-1030. [CrossRef]

27. Stringer, P. Energy use: The human dimension: Paul, C. Stern and Elliot Aronson (eds.), Freeman, New York, 1984. pp. 237, £28.50 (board), £14.50 (paper). (Book Review). J. Econ. Psychol. 1985, 6, 417-420.

28. Eichhammer, W.; Fleiter, T.; Schlomann, B.; Faberi, S.; Fioretto, M.; Piccioni, N.; Lechtenböhmer, S.; Schüring, A.; Resch, G. Study on the Energy Savings Potentials in EU Member States, Candidate Countries and EEA Countries: Final Report; Fraunhofer Inst. for Systems and Innovation Research: Karlsruhe, Germany, 2009.

29. Tuominen, P.; Klobut, K.; Tolman, A.; Adjei, A.; de Best-Waldhober, M. Energy savings potential in buildings and overcoming market barriers in member states of the European Union. Energy Build. 2012, 51, 48-55. [CrossRef]

30. Scott, S. Household energy efficiency in Ireland: A replication study of ownership of energy saving items. Energy Econ. 1997, 19, 187-208. [CrossRef]

31. Martinsson, J.; Lundqvist, L.J.; Sundström, A. Energy saving in Swedish households. The (relative) importance of environmental attitudes. Energy Policy 2011, 39, 5182-5191. [CrossRef]

32. Azizi, S.; Nair, G.; Olofsson, T. Analysing the house-owners' perceptions on benefits and barriers of energy renovation in Swedish single-family houses. Energy Build. 2019. [CrossRef]

33. Rogers, E.M. Diffusion of Innovations, 5th ed.; Free Press: New York, NY, USA, 2003; ISBN 0743222091.

34. Gram-Hanssen, K. Retrofitting owner-occupied housing: Remember the people. Build. Res. Inf. 2014, 42, 1-5. [CrossRef]

35. Buser, M.; Carlsson, V. What you see is not what you get: Single-family house renovation and energy retrofit seen through the lens of sociomateriality. Constr. Manag. Econ. 2017, 35, 276-287. [CrossRef] 
36. Nair, G.; Gustavsson, L.; Mahapatra, K. Factors influencing energy efficiency investments in existing Swedish residential buildings. Energy Policy 2010, 38, 2956-2963. [CrossRef]

37. Achtnicht, M.; Madlener, R. Factors influencing German house owners' preferences on energy retrofits. Energy Policy 2014, 68, 254-263. [CrossRef]

38. Karytsas, S. An empirical analysis on awareness and intention adoption of residential ground source heat pump systems in Greece. Energy Policy 2018, 123, 167-179. [CrossRef]

39. Agresti, A. Categorical Data Analysis, 3rd ed.; Wiley Series in Probability and Statistics; Wiley-Interscience: Hoboken, NJ, USA, 2013; ISBN 1-118-71085-1.

40. Mahapatra, K.; Nair, G.; Gustavsson, L. Swedish energy advisers' perceptions regarding and suggestions for fulfilling homeowner expectations. Energy Policy 2011, 39, 4264-4273. [CrossRef]

41. O’Brien, W.; Wagner, A.; Schweiker, M.; Mahdavi, A.; Day, J.; Kjærgaard, M.B.; Carlucci, S.; Dong, B.; Tahmasebi, F.; Yan, D.; et al. Introducing IEA EBC annex 79: Key challenges and opportunities in the field of occupant-centric building design and operation. Build. Environ. 2020, 178, 106738. [CrossRef]

42. Kim, J.; de Dear, R. Nonlinear relationships between individual IEQ factors and overall workspace satisfaction. Build. Environ. 2012, 49, 33-40. [CrossRef]

43. Beasley, T.M.; Schumacker, R.E. Multiple regression approach to analyzing contingency tables: Post hoc and planned comparison procedures. J. Exp. Educ. 1995, 64, 79-93. [CrossRef]

44. García-pérez, M.A.; Núñez-antón, V. Cellwise Residual Analysis in Two-Way Contingency Tables. Educ. Psychol. Meas. 2003, 63, 825-839. [CrossRef]

45. Tjørring, L. We forgot half of the population! The significance of gender in Danish energy renovation projects. Energy Res. Soc. Sci. 2016, 22, 115-124. [CrossRef]

46. Lynch, R.M. Irritation and clean-up methods following installation of cellulose attic insulation in one NJ home. Energy Eng. 2011, 108, 26-41. [CrossRef]

47. Stieß, I.; Dunkelberg, E. Objectives, barriers and occasions for energy efficient refurbishment by private homeowners. J. Clean. Prod. 2013, 48, 250-259. [CrossRef]

48. Nair, G.; Mahapatra, K.; Gustavsson, L. Implementation of energy-efficient windows in Swedish single-family houses. Appl. Energy 2012, 89, 329-338. [CrossRef]

49. Klockner, C.A.; Nayum, A. Specific barriers and drivers in different stages of decision-making about energy efficiency upgrades in private homes. Front. Psychol. 2016, 7. [CrossRef]

50. Wilson, C.; Dowlatabadi, H. Models of Decision Making and Residential Energy Use. Annu. Rev. Environ. Resour. 2007, 32, 169-203. [CrossRef]

51. Nair, G. Implementation of Energy Efficiency Measures in Swedish Single-Family Houses. Ph.D. Thesis, Mid Sweden University, Östersund, Sweden, 2012.

Publisher's Note: MDPI stays neutral with regard to jurisdictional claims in published maps and institutional affiliations.

(C) 2020 by the authors. Licensee MDPI, Basel, Switzerland. This article is an open access article distributed under the terms and conditions of the Creative Commons Attribution (CC BY) license (http://creativecommons.org/licenses/by/4.0/). 